\title{
Controlled Growth and Cathodoluminescence Pro- perty of ZnS nanobelts with Large Aspect Ratio
}

\author{
Xiang $\mathrm{Wu}^{1,2, *}$, Ying Lei ${ }^{1}$, Yufeng Zheng ${ }^{2}$ and Fengyu $Q u^{1}{ }^{1 *}$
}

ZnS nanobelts with large aspect ratio are successfully synthesized on a large scale through thermally evaporating of $\mathrm{ZnS}$ powder with a trace of $\mathrm{SnO}_{2}$ powder using gold coated Si wafer as the substrate at $1100^{\circ} \mathrm{C}$. The results indicate that the as-obtained $\mathrm{ZnS}$ nanobelts are about $10 \mathrm{~nm}$ in thickness and hundreds of micrometers in length, and the aspect ratio reaches more than $10^{4}$. Substrate dependent experiments are conducted to better study the growth mechanism of the $\mathrm{ZnS}$ nanobelts. Subsequently, optical properties of the as-synthesized $\mathrm{ZnS}$ nanobelts are also investigated by using a cathodoluminescence (CL) system, which shows the existence of a strong ultraviolet emission at $342 \mathrm{~nm}$ and two poor emission peaks at $522 \mathrm{~nm}$ and $683 \mathrm{~nm}$ at room temperature, respectively.

Keywords: Semiconductor; ZnS; Nanobelts; Cathodoluminescence

Citation: Xiang Wu, Ying lei, Yufeng Zheng and Fengyu Qu, "Controlled Growth and Cathodoluminescence Property of ZnS Nanobelts with Large Aspect Ratio", Nano-Micro Lett. 2, 272-276 (2010). doi:10.3786/nml.v2i4.p272-276

Different from the geometry shapes of the nanorod, nanowire and nanotube, the nanobelt possesses a rectanglelike cross section with large width-to-thickness ratio and high aspect ratio. Nanobelts of different components with various morphologies have been synthesized, including elements $[1,2]$, oxides $[3,4]$, nitrides [5], sulfides [6-11] even ternary compounds [12, 13] since Pan et al. first reported the formation of nanobelts of semiconductor oxides in 2001 [14]. With the special geometry shapes and microstructure, the beltlike nanostructures have been the research focus due to their unique physical and chemical properties, such as optical [15, 16], electrical [17] and sensor [18, 19], field emission [20, 21], optoelectronic properties [22-24], and so on. Therefore, it is important to obtain the desiring nanobelts with uniform dimensions and sizes and controllable structures for the integration of nanodevices based nanobelt building blocks.

As an important semiconductor compound material, $\mathrm{ZnS}$ with a direct wide band gap (3.68 eV) and exciton binding energy of $40 \mathrm{meV}$ at room temperature, has a high refractive index and a high transmittance in the visible range [25]. Many efforts have been made on synthesis of one dimensional (1D)
$\mathrm{ZnS}$ nanobelts in recent years by a variety of methods. Zhang et al. reported bicrystal $\mathrm{ZnS}$ nanobelts through a chemical vaporation method on $\mathrm{Si}$ and $\mathrm{KCl}$ substrates, respectively [26]. Meng et al synthesized dart-shaped tricrystal $\mathrm{ZnS}$ nanoribbons by simple thermal evaporation of the mixture of $\mathrm{ZnS}$ and $\mathrm{SiO}$ and studied the growth mechanism in detail [27]. Hao et al. investigated the growth of periodically twinned nanobelts of $\mathrm{ZnS}$ and thought the mass diffusion played an important role in the growth process of the twinned $\mathrm{ZnS}$ nanobelts [28]. Fang et al. synthesized ultrafine $\mathrm{ZnS}$ nanobelts as good field emitters [21]. Herein, we successfully fabricated $\mathrm{ZnS}$ nanobelts with large aspect ratio by adjusting the substrate types and the evaporation rate, and studied the CL properties of the as-obtained products. $\mathrm{ZnS}$ nanobelts reported here are good candidates for optical and optoelectronic devices.

$\mathrm{ZnS}$ nanobelts with large aspect ratio were synthesized through a thermal evaporation process in a horizontal tube furnace with $\mathrm{Au}$ catalyst on $\mathrm{Si}$ substrate. A Si wafer $(1 \mathrm{~cm}$ in length and $5 \mathrm{~mm}$ in width) was placed downstream, which is 20 $\mathrm{cm}$ away from the source material. $1 \mathrm{~g}$ commercial-grade $\mathrm{ZnS}$ powder with $0.2 \mathrm{~g} \mathrm{SnO}_{2}$ was placed in the center of a 
single-zone tube furnace and evacuated for 2 hours to purge oxygen from the chamber, then the furnace was heated to $1100^{\circ} \mathrm{C}$ at a rate of $20^{\circ} \mathrm{C} / \mathrm{min}$ and keep at this temperature for 1h. A carrier gas of high-purity Ar was kept flowing at a rate of $50 \mathrm{sccm}$. The pressure inside the tube was maintained at 300 Torr during the whole experiment. After the furnace was cooled to room temperature, a gray wool-like product was deposited on Si substrate. A series of control experiments were conducted by changing the substrate types. The collected products were characterized by a scanning electron microscope (SEM, Hitachi S-4800) equipped with an energy-dispersive X-ray detector (EDX, INCA300), and a transmission electron microscope (JEOL JEM-3010). Cathodoluminescence properties are investigated by means of a thermal field emission scanning electron microscope (Hitachi S4200) equipped with a CL system. The CL spectra and images are taken at room temperature at $5 \mathrm{kV}$ and $70 \mathrm{pA}$.
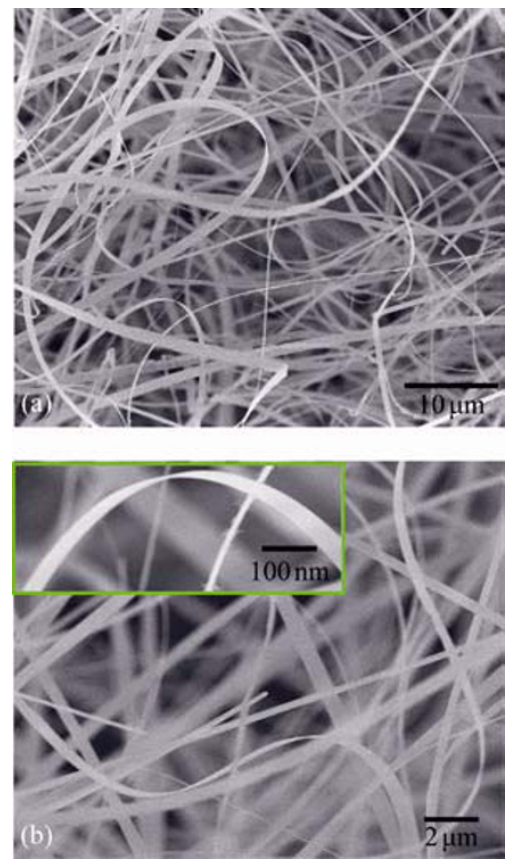

FIG. 1. SEM images of the as-obtained ZnS nanobelts (a) General SEM image of the as-synthesized product; (b) High magnification SEM image, the inset is a local SEM image of $\mathrm{ZnS}$ nanobelt.

Figure 1 shows SEM images of the as-grown $\mathrm{ZnS}$ nanobelts. A low magnification SEM image in Fig. 1(a) indicates the nanobelts are tens of micrometers in length. Fig. 1(b) is a high magnification SEM image, indicating a good bending charac- teristic of the nanobelt. Each nanobelt has a uniform width along the entire length direction; the inset in Fig. 1(b) is a local SEM image, showing clearly the thickness of only about $10 \mathrm{~nm}$. A typical XRD pattern from the as-grown product is shown in Fig. 2(a), where all the diffraction peaks can be indexed to wurzite structured $\mathrm{ZnS}$ with lattice constants of
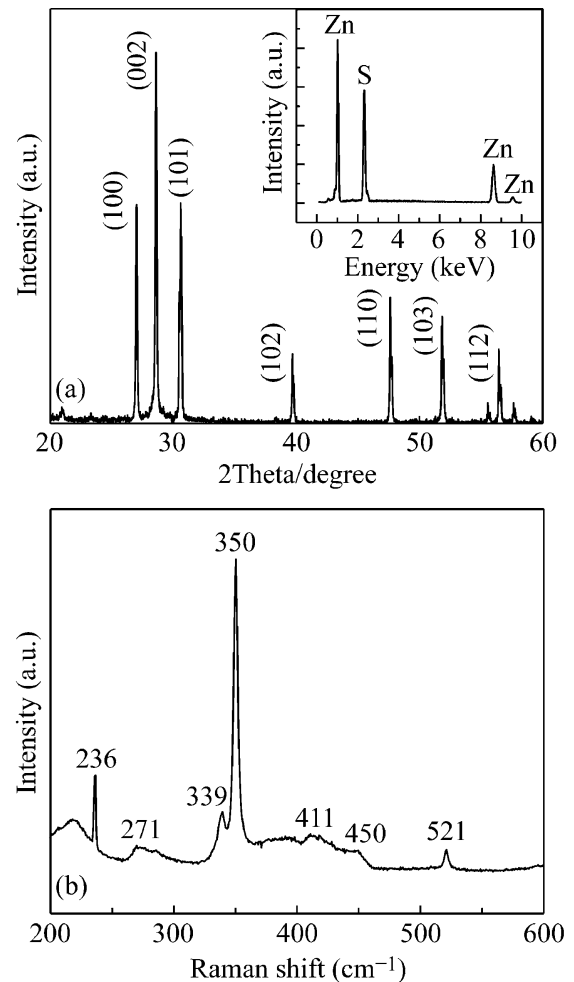

FIG. 2. (a) Raman spectrum of the as-synthesized $\mathrm{ZnS}$ nanobelts (b) XRD pattern of as-synthesized $\mathrm{ZnS}$ nanobelts.

$\mathrm{a}=0.382 \mathrm{~nm}$ and $\mathrm{c}=0.625 \mathrm{~nm}$ (PCPDS card: $36-1450)$, no $\mathrm{SnO}_{2}$ peaks are found, which means the as-synthesized $\mathrm{ZnS}$ nanobelt has a high purity. The inset in Fig. 2(a) is an EDS spectrum, which is consistent with the XRD pattern result. Raman spectrum from the as-grown nanobelts is shown in Fig. 2(b) the much weaker peak at $521 \mathrm{~cm}^{-1}$ is from $\mathrm{Si}$ substrate. The dominate spectrum is $350 \mathrm{~cm}^{-1}$, which is designated as longitudinal optical (LO) phonon mode. The weaker peak at 271 $\mathrm{cm}^{-1}$ is associated with transverse optical (TO) phonon mode. Some phonon peaks by these election rules will become stronger in a particular scattering geometry due to all of nanobelts grown along the same direction, the same as that of the wires reported by Lin et al [29]. Besides the characteristic peaks, Raman peaks located at 236, 339, 411 and $450 \mathrm{~cm}^{-1}$ are also observed, which can be attributed to plasmon-enhanced resonant Raman effect [30].

TEM is used to further study the microstructures of the as-grown $\mathrm{ZnS}$ nanobelts. Figures 3(a) and 3(b) show low magnification TEM and HRTEM images, respectively. The HRTEM image reveals the nanobelts of $\mathrm{ZnS}$ are structurally uniform. The measured spacing of $0.626 \mathrm{~nm}$ corresponds to the distance between (001) plane of the $\mathrm{ZnS}$ nanobelts. The inset in Fig. 3(b) is the selected area electron diffraction (SAED) pattern 


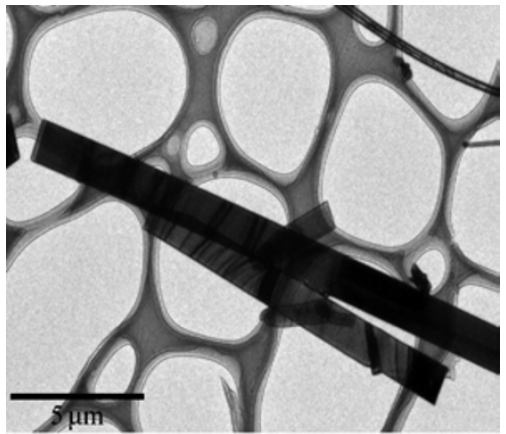

(a)

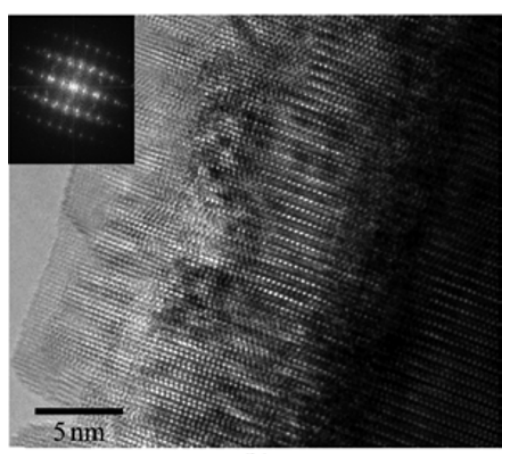

(b)

FIG. 3. TEM images of the as-obtained $\mathrm{ZnS}$ nanobelts (a) Low magnification TEM image; (b) HRTEM image, the inset is the corresponding SAED pattern.

of the as-grown $\mathrm{ZnS}$ nanobelt, confirming that the as-grown $\mathrm{ZnS}$ nanobelt is single crystal and grows along [001] direction.

To better investigate the formation of $\mathrm{ZnS}$ nanobelts with large aspect ratio, substrate dependent comparison experiments were conducted. When using tungsten thread as the deposition substrate, the beltlike structured $\mathrm{ZnS}$ still exist, but the thickness is about $100 \mathrm{~nm}$, as shown in Fig. 4(a). When tungsten wafer substitutes for tungsten thread as the substrate (see Figure 4(b)), the thickness of $\mathrm{ZnS}$ nanobelts are larger and their length became shorter. The inset in Fig. 4(b) is the local enlarged SEM image; one can see the thickness is about $300 \mathrm{~nm}$. The phenomenon indicates that though the same type substrate, different surface of the substrate (smooth or curved) have crucial effect on the size and dimension of the as-obtained $\mathrm{ZnS}$ product.

Due to using gold coated Si wafer as the substrate, $\mathrm{ZnS}$ nanobelts with large aspect ratio can be formed. Otherwise, only large scale $\mathrm{ZnS}$ nanorod arrays are formed when using bare silicon wafer as the substrate, as shown in Fig. 4(c) and 4(d), which indicate that gold catalyst play an important role in the growth of $\mathrm{ZnS}$ nanobelts with large aspect ratio. Therefore, the growth of $\mathrm{ZnS}$ nanobelt with large aspect ratio is dominated by vapor-liquid-solid (VLS) mechanism [31]. At first, ZnS powder evaporates into $\mathrm{Zn}$ vapor and sulfur vapor at high temperature. As the reaction procceeds, Zinc vapor diffuses and meets the sulfur vapor together with the carrier gas and dissolve into liquid gold catalyst and form a small liquid droplet. $\mathrm{ZnS}$ crystals shall precipitates from solid -liquid interface with the favorite growth direction when the concentration of $\mathrm{Zn}$ and $\mathrm{S}$ atoms in the droplet is greater than the saturation. No gold nanoparticles were found here, it is possible that the Au particle catalysts have been evaporated when the growth of the $\mathrm{ZnS}$ nanobelts finishes, which is consistent with the explanation to the growth of $\mathrm{ZnO}$ nanowires and nanohelices $[32,33]$. Previously we reported the synthesis of fishbonelike $\mathrm{ZnS}$ nanostructures through using ITO glass as the substrate [34]. It shows that each substrate has
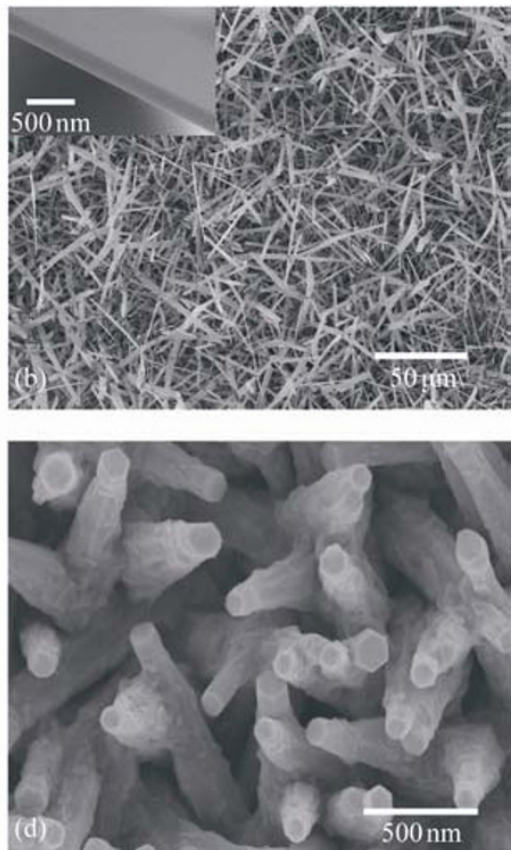

FIG. 4. SEM images of the as-synthesized products in the different substrates (a) Tungsten thread; (b) Tungsten wafer; (c-d) silicon wafer. 
different interface with the as-grown $\mathrm{ZnS}$ nanostructures, which determines the nucleation rates of the nanoparticles and then the final morphologies of the as-obtained product. Therefore, in synthesizing the nanostructures by thermal evaporation method, besides considering growth temperature $[35,36]$, choosing the suitable deposition substrate is also important for getting the desired nanostructures for future micro/nanodevices integration.

There are many reports about photoluminescence and cathodoluminescence of semiconductor nanostructures [37-40]. Cathodoluminescence measurement of $\mathrm{ZnS}$ nanobelts with large aspect ratio was conducted at room temperature at $5 \mathrm{kV}$ and $70 \mathrm{pA}$. CL spectrum of the as-synthesized ultrathin $\mathrm{ZnS}$ nanobelts is showed in Figure 5, where there are three emission peaks at $342 \mathrm{~nm}, 522 \mathrm{~nm}$ and $683 \mathrm{~nm}$, respectively. The stronger emission peak at $342 \mathrm{~nm}$ can be ascribed to intrinsic characteristic emission. Due to quantum effect there is a slight shift of $5 \mathrm{~nm}$, comparing to bulk $\mathrm{ZnS}$ powder. About the peak at $522 \mathrm{~nm}$, Liu et al. studied the Cd-doped $\mathrm{ZnS}$ nanostructures and attributed it to $\mathrm{Cd}$ doping [41]. $\mathrm{Xu}$ et al. have observed a green emission band at $507 \mathrm{~nm}$ in $\mathrm{Cu}$-doped $\mathrm{ZnS}$ nanocrystals [42]. Liang et al proposed it is likely related to the gold impurity induced deep level emission [43]. In the present experiment, gold was also employed as catalyst. Therefore the green emission at $522 \mathrm{~nm}$ can be attributed to gold impurity. The origin of the red light emission about $\mathrm{ZnS}$ nanostructures is seldom explained, Liu et al studied $\mathrm{Cd}$ and $\mathrm{Mn}$ co-doped $\mathrm{ZnS}$ nanostructures and thought the red light emission originated from the interaction of $\mathrm{Mn}$ and $\mathrm{Cd}$ pairs. This emission could be strengthened by adjusting the Mn and $\mathrm{Cd}$ content in $\mathrm{ZnS}$ [44]. In our work, no $\mathrm{Cd}$ or $\mathrm{Mn}$ doping, therefore it is no the case for the reported $\mathrm{ZnS}$ nanobelts here. We propose the emission perhaps happen during electron transit from oxygen vacancy to valence band due to a trace of

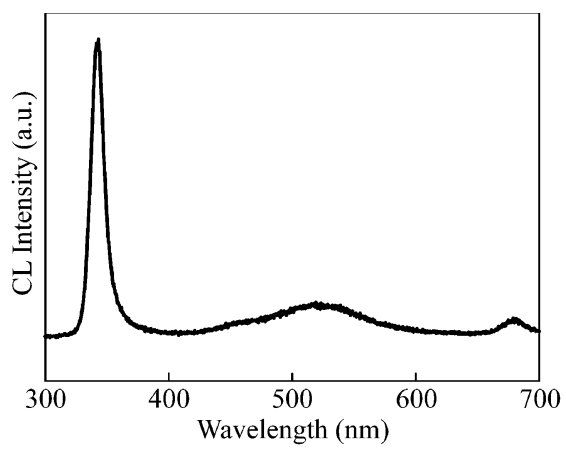

FIG. 5. CL spectrum of the as-obtained $\mathrm{ZnS}$ nanobelts.

the addition of $\mathrm{Sn}$ element. More systematic studies shall be conducted to full understand the origin of this emission band and shall be reported otherwhere.
In summary, $\mathrm{ZnS}$ nanobelts with large aspect ratio have been synthesized by using gold coated Si wafer as the substrate. The as-grown $\mathrm{ZnS}$ nanobelts with high width-thickness ratio are about $10 \mathrm{~nm}$ in thickness and tens of micrometers in length. Substrate types play the important roles in determining the size and thickness of the as-obtained products. Gold mediated VLS process is responsible for the nucleation and growth of the $\mathrm{ZnS}$ nanobelts with large aspect ratio. CL spectrum shows that there are a stronger ultraviolet emission peak at $342 \mathrm{~nm}$ and two poor visual peaks at $522 \mathrm{~nm}$ and $683 \mathrm{~nm}$.

This work was sponsored by the Scientific Research Fund of Heilongjiang Provincial Education Department (11551117) and China Postdoctoral Foundation (20090460875), Pre-research Fund (2009KYG-01) and Youth Skeleton Teacher Fund (10KXQ-07) of Harbin Normal University. We thank Dr. Kentaro Watanabe for his kind help in CL test.

\section{References}

1. A. M. Qin, Z. Li, R. S. Yang, Y. D. Gu, Y. Z. Liu and Z. L. Wang, Solid Stat. Commun. 148, 145 (2008). doi:10.1016/ j.ssc.2008.07.039

2. D. P. Wang and Q. Chen, J Phys. Chem. C 112, 15129 (2008).

3. Z. R. Dai, Z. W. Pan and Z. L. Wang, Adv. Funct. Mater. 13, 9 (2003). doi:10.1002/adfm.200390013

4. L. Zhang, X. Yang, J. Dong and Y. Xie, Chem. Mater. 21, 5681 (2009). doi:10.1021/cm9023887

5. H. B. Zeng, C. Y. Zhi, Z H. Zhang, X. L. Wei, X. B. Wang, W. L. Guo, Y. Bando and D. Golberg, Nano Lett. 10, 5049 (2010). doi:10.1021/n1103251m

6. L. Li, P. S. Lee, C. Y. Yan, T. Y. Zhai, X. S. Fang, M. Y. Liao, Y. Koide, Y. Bando and D. Golberg, Adv. Mater. 22, 5145(2010). doi:10.1002/adma.201002608

7. F. Lu, W. P. Cai, Y. G. Zhang, Y. Li, F. Q. Sun, S. H. Seo and S. O. Cho, J Phys. Chem. C 111, 13385 (2007).

8. L. Li, X. S. Fang, T. Y. Zhai, M. Y. Liao, U. K. Gautam, X. C. Wu, Y. Koide, Y. Bando and D. Golberg, Adv. Mater. 22, 4151 (2010). doi:10.1002/adma.201001413

9. X. C. Wu, Y. R. Tao and Q. X. Gao, Nano Res. 2, 558 (2009). doi:10.1007/s12274-009-9055-2

10. P. C. Wu, R. M. Ma, C. Liu, T. Sun, Y. Ye and L. Dai, J Mater. Chem. 15, 2125 (2009). doi:10.1039/b822518d

11. L. Li, P. C. Wu, X. S. Fang, T. Y. Zhai, L. Dai, M. Y. Liao, Y. Koide, H. Q. Wang, Y. Bando and D. Golberg, Adv. Mater. 22, 3161(2010). doi:10.1002/adma.201000144 
12. Y. Su, S. Li, L. Xu, Y. Q. Chen, Q. T. Zhou, B. Peng, S. Yin, X. Meng, X. M. Liang and Y. Feng, Nanotechnology 17, 6007 (2006). doi:10.1088/0957-4484/17/24/017

13. Y. Li and X. L. Ma, Phys. Stat. Sol. A 202, 435 (2005). doi:10.1002/pssa.200406924

14. Z. W. Pan,Z. R. Dai and Z. L. Wang, Science 291, 1947 (2001). doi:10.1126/science. 1058120

15. G. Z. Shen, D. Chen, P. C. Chen and C. W. Zhou, ACS Nano 3, 1115 (2009). doi:10.1021/nn900133f

16. Z. Fang, K. B. Tang, J. M. Shen, G. Z. Shen and Q. Yang, Cryst. Growth Des. 7, 2254 (2007). doi:10.1021/cg06 $\underline{07755}$

17. J. Lin, Y. Huang, Y. Bando, C. C. Tang, C. Li and D. Golberg, ACS Nano 4, 2452 (2010). doi:10.1021/nn100 254f

18. Y. G. Li, P. Feng, X. Y. Xue, S. L. Shi, X. Q. Fu, C. Wang, Y. G. Wang and T. H. Wang, Appl. Phys. Lett. 90, 042109 (2007). doi:10.1063/1.2432278

19. E. Comini, G. Faglia, G. Sberveglieri, Z. W. Pan and Z. L.Wang, Appl. Phys. Lett. 81, 1869 (2002). doi:10.1063/ $\underline{1.1504867}$

20. H. Zhang, W. Q. Ding, K. He and M. Li, Nanoscale. Res. Lett. 5, 1264 (2010). doi:10.1007/s11671-010-9635-9

21. X. S. Fang,Y. Bando, G. Z. Shen,C. H. Ye, U. K. Gautam, P. M. F. J. Costa, C. Y. Zhi, C. C. Tang and D. Golberg, Adv. Mater. 19, 2593 (2007). doi:10.1002/adma.2007 $\underline{00078}$

22. X. S. Fang, S. L. Xiong, T. Y. Zhai, Y. Bando, M. Y. Liao, U. K. Gautam, Y. Koide, X. G. Zhang, Y. T. Qian and D. Golberg, Adv. Mater. 21, 5016 (2009). doi:10.1002/adma. $\underline{200902126}$

23. C. S. Lao, Y. Li, C. P. Wong and Z. L. Wang, Nano Lett. 7, 1323 (2007). doi:10.1021/n1070359m

24. J. H. He, Y. H. Lin, M. E. Mcconney, W. Tsukruk, Z. L. Wang and G. Bao, J Appl. Phys. 102, 084303 (2007). doi:10.1063/1.2798390

25. S.Yamaga, A.Yoshikawa and H.Kasai, J. Cryst. Growth 86, 252 (1998). doi:10.1016/0022-0248(90)90725-Z

26. Z. X. Zhang, J. X. Wang, H. J. Yuan, Y. Gao, D. F. Liu, L. Song, Y. J. Xiang, X. W. Zhao, L. F. Liu, S. D. Luo, X. Y. Dou, S. C. Mou,W. Y. Zhou and S. S. Xie, J. Phys. Chem. B 109, 18352 (2005). doi:10.1021/jp052199d

27. X. Fan, X. M. Meng, X. H. Zhang, W. S. Shi, W. J. Zhang, J. A. Zapien, C. S. Lee and S. T. Lee, Angew. Chem. Int. Ed. 45, 2568 (2006). doi:10.1002/anie.200504069
28. Y. F. Hao, G. W. Meng, Z. L. Wang, C. H. Ye and L. D. Zhang, Nano Lett. 6, $1650 \quad$ (2006). doi:10.1021/n1060695n

29. M. Lin, T. Sudhiranjan, C. Boothroyd and K. P. Loh, Chem. Phys. Lett. 400, 175 (2004). doi:10.1016/j.cplett. 2004.10.115

30. M. Abdulkhadar and B. thomas, Nanostruc. Mater. 5, 289 (1995). doi:10.1016/0965-9773(95)00237-9

31. R. S. Wagner and W. C. Ellis, Appl. Phys. Lett. 4, 89 (1964). doi:10.1063/1.1753975

32. S. Bae, J. Lee, H. Jung, J. Park and J. Ahn, J. Am. Chem. Soc. 127, 10802 (2005). doi:10.1021/ja0534102

33. X. Wu, W. Cai and F. Y. Qu, Chin. Phys. B 18, 1669 (2009). doi:10.1088/1674-1056/18/4/065

34. X. Wu, F. Y. Qu, G. Z. Shen and W. Cai, J. Alloys Compd. 482, L32 (2009). doi:10.1016/j.jallcom.2009.04.070

35. X. S. Fang, C. H. Ye, L. D. Zhang, Y. H. Wang and Y. C. Wu, Adv. Funct. Mater. 15, 63 (2005). doi:10.1002/adfm. $\underline{200305008}$

36. X. Wu, J. H. Sui, W. Cai and P. Jiang, Chin. Phys. Lett. 25, 737 (2008). doi:10.1088/0256-307X/25/2/104

37. H. B. Zeng, G. T. Duan, Y. Li, S. K. Yang, X. X. Xu and W. P. Cai, Adv. Funct. Mater. 20, 561(2010). doi:10.1002/ dfm.200901884

38. H. B. Chen, X. Wu, L. H. Gong, C. Ye, F. Y. Qu and G. Z. Shen, Nanoscale Res. Lett. 5, 570 (2010). doi:10.1007/ 11671-009-9506-4

39. Y. T. Han, X. Wu, G. Z. Shen, B. Dierre, L. H. Gong, F. Y. Qu, Y. Bando, T. Sekiguchi, F. Fabbri and D. Golberg, J. Phys. Chem. C 114, 8235(2010). doi:10.1021/jp100942m

40. H. B. Zeng, W. P. Cai, Y. Li, J. L. Hu and P. S. Liu, J. Phys. Chem. B 109, 18260(2005). doi:10.1021/jp052258n

41. J. Z. Liu, P. X. Yan, G. H. Yue, J. B. Chang, D. M. Qu and R. F. Zhuo, J. Phys. D: Appl. Phys. 39, 2352 (2006).

42. S. J. Xu, S. J. Chua, B. Liu, L. M. Gan, C. H. Chew and G. Q. Xu, Appl. Phys. Lett. 73, 478(1998). doi:10.1063/. $\underline{121906}$

43. H. Liang, Y. Shimizu, T. Sasaki, H. Umehara and N. Koshizaki, J. Phys. Chem. B 108, 9728 (2004). doi:10. $\underline{1021 / \mathrm{p} 037963 \mathrm{f}}$

44. J. Z. Liu, P. X.Yan, G. H. Yue, J. B. Chang, D. M. Qu and R. F. Zhuo. J. Phys. D: Appl. Phys. 39,2352(2006). doi:10. $\underline{1088 / 0022-3727 / 39 / 11 / 006}$ 